\title{
The vegetative arctic freshwater green alga Zygnema is insensitive to experimental UV exposure
}

\author{
Andreas Holzinger ${ }^{\mathrm{a}, *}$, Michael Y. Roleda ${ }^{\mathrm{b}}$, Cornelius Lütz ${ }^{\mathrm{a}}$ \\ ${ }^{a}$ Institute of Botany, Department of Physiology and Cell Physiology of Alpine Plants, Sternwartestrasse 15, A 6020 Innsbruck, Austria \\ ${ }^{\mathrm{b}}$ Institute for Polar Ecology, University of Kiel, Wischhofstr. 1-3, Bldg. 12, D-24148 Kiel, Germany
}

A R T I C L E I N F O

\section{Article history:}

Received 18 May 2009

Received in revised form 18 June 2009

Accepted 19 June 2009

\section{Keywords:}

Global climate change

Green algae

Lipid bodies

Photosynthesis

Ultrastructure

UV

\begin{abstract}
A B S T R A C T
The physiological performance and ultrastructural integrity of the vegetative freshwater green alga Zygnema sp., growing under ambient polar day solar radiation and after exposure to experimentally low radiation, but with high UVR:PAR ratio were investigated. In the laboratory, algae were exposed to low photosynthetic active radiation $\left(P A R=P, 400-700 \mathrm{~nm}, 20 \mu \mathrm{mol} \mathrm{m}^{-2} \mathrm{~s}^{-1}\right)$, PAR + UV-A = PA (320$\left.400 \mathrm{~nm}, 4.00 \mathrm{~W} \mathrm{~m}^{-2}=\mathrm{UV}-\mathrm{A}\right)$ and PAR + UV-A + UV-B = PAB (280-320 nm, $\left.0.42 \mathrm{~W} \mathrm{~m}^{-2}=\mathrm{UV}-\mathrm{B}\right)$ for $24 \mathrm{~h}$ at $7{ }^{\circ} \mathrm{C}$. Photosynthetic performance and ultrastructure of ambient solar radiation-exposed (field control) and experimentally treated Zygnema samples were assessed using chlorophyll fluorescence, and transmission electron microscopy (TEM). No significant treatment effect was observed in the photosynthesis-irradiance curve parameters. Exclusion of the UV-B spectrum in the laboratory treatment caused significantly lower effective photosynthetic quantum yield compared to samples exposed to the whole radiation spectrum. TEM revealed no obvious differences in the ultrastructure of field control and laboratory P-, PA- and PAB-exposed samples. Substantial amounts of lipid bodies, visualized by Sudan IV staining, were observed in all samples. Chloroplasts contained numerous plastoglobules. Organelles like mitochondria, Golgi bodies and the nucleus remained unaffected by the radiation exposures. Zygnema is well adapted to ambient solar radiation, enabling the alga to cope with experimental UV exposure and it is expected to persist in a scenario with enhanced UV radiation caused by stratospheric ozone depletion.
\end{abstract}

(c) 2009 Elsevier Ltd. All rights reserved.

\section{Introduction}

A relatively diverse flora consisting of Cyanobacteria, Bacillariophyta, Chrysophyta, Chlorophyta and Rhodophyta inhabits the streams and hydro-terrestrial (cf. Elster, 2002 for the terminology) environment of the arctic tundra (Kim et al., 2008; Komulayanen, 2008; Sheath et al., 1996; Stockmayer, 1906). In particular, epipelic algae render several ecosystem functions including biostabilisation of sediments, regulation of benthic-pelagic nutrient cycling, and primary production, among others (Poulíčková et al., 2008). Most of these species tolerate prolonged freezing and desiccation by forming resistant vegetative cells, abundant reserves and low molecular weight solutes to lower the cellular freezing point (Sheath et al., 1996).

Conspicuous patches of epipelic Zygnema sp. mats are observed close to the high Arctic international research base in Ny-Ålesund (Kim et al., 2008). The absence of conjugating stages undermined the possibility to identify the species of the Zygnema isolate (cf.

\footnotetext{
* Corresponding author. Fax: +43 5125072715.

E-mail address: Andreas.Holzinger@uibk.ac.at (A. Holzinger).
}

Brook and Johnson, 2002). Our observation was, however, in concordance with the previous reports of Stockmayer (1906) and Kim et al. (2008). Moreover, a Zygnema isolate from Svalbard did not undergo conjugation even after over one year cultivation in the laboratory (Kim et al., 2008). Sterile filaments of Zygnema are not only reported in the high Arctic (e.g. Stockmayer, 1906; Kim et al., 2008) but also in thermal waters (Stoyneva, 2003). The strong tendency in the occurrence of asexual populations are reported in a species' geographical limits (e.g. further north of Northern Hemisphere), at high altitudes, and in resource poor environments (Billingham et al., 2003; Eckert, 2002; Kearney, 2003; Peck et al., 1998). On the other hand, the greater sensitivity of the sexual reproductive phase compared to the asexual vegetative phase to environmental stress factors, i.e. ultraviolet radiation, is reported in Ulva intestinalis (Cordi et al., 2001) and Urospora penicilliformis (Roleda et al., 2009a). Therefore, the evolution of genetic infertility at the geographical margins of the species' ranges may occur if sterility is associated with enhanced growth and survival in extreme environments (Eckert, 2002).

The Kongsfjorden and Ny-Ålesund have become a model ecosystem for studies on Arctic environments, where global climate change can be easily studied, when compared to temperate 
latitudes. The seasonal depletion of stratospheric ozone concentration over the Polar Regions initiated numerous research efforts to elucidate the biological consequences of the related increase in UV-B radiation reaching the biosphere. Whereas seasonal ozone depletion is regularly observed in the Antarctic since more than 30 years, significant depletion of the Arctic ozone layer sporadically occurred in some years (e.g. 1999-2000, 2001-2002, and 20042005) during late winter/spring period (January-April) (Dahlback, 2002; Hessen, 2002; Fahey, 2003; Jin et al., 2006; Muscari et al., 2007). Even under non-depleted ozone conditions, UV-B still presents potential negative impacts to photosynthetic organisms. For example, several physiological and metabolic processes, i.e. photosynthesis, respiration, growth and reproduction, as well as molecular and ultrastructural integrity are compromised under ultraviolet radiation (UVR; e.g. Björn et al., 1999; Björn, 2002, 2008; Caldwell et al., 1998; Holzinger and Lütz, 2006; Roleda et al., 2007).

Zygnema is often found in shallow puddle and streamlets, and on surface of water-saturated soil and stone particles exposed to ambient solar radiation. Despite this, no study is available on the UV-susceptibility or tolerance of this species. To our knowledge, one of the few studies mentioning Zygnema in relation to UVR effects is by Helbling et al. (2001), who did not specifically investigate Zygnema, but the effect of UVR on a natural phytoplankton community, where this alga was not dominating.

In our study, we examined the photosynthetic performance and ultrastructure of field-collected sterile filaments of Zygnema exposed to ambient polar day solar radiation (field control) and after exposure to different spectral quality with relatively low irradiance of PAR, UV-A and UV-B to obtain high UVR:PAR ratio in the laboratory. The response of Zygnema sp. to UVR was discussed in relation to its extreme habitat and the significance of vegetative propagation.

\section{Materials and methods}

\subsection{Plant material}

Epipelic Zygnema sp. mats (Fig. 1a) were collected on the soil close to a freshwater runlet in Ny-Ålesund, Spitsbergen, Norway $\left(78^{\circ} 55.5^{\prime} \mathrm{N}, 11^{\circ} 56.0^{\prime} \mathrm{E}\right)$. The algal mats were easily dislodged, rinsed briefly and brought to the laboratory. Circular discs, with a diameter of $2 \mathrm{~cm}(\sim 2-3 \mathrm{~mm}$ thick) were punched out of the mats (Fig. 1b). Twelve algal discs were filled into plastic cell culture dishes, covered with corresponding cut-off filter foils and exposed under the lamps (see below). In addition, samples were lyophilized for $24 \mathrm{~h}$ on Whatman Filter paper for lipid staining and SEM.

\subsection{Light microscopy}

Cellular structures of field-collected samples of Zygnema sp. were investigated using a Zeiss Axioplan Microscope equipped with a camera (Canon 70, Tokyo, Japan) in Spitsbergen. A Zeiss Axiovert $200 \mathrm{M}$ Light Microscope (Carl Zeiss AG, Oberkochen, Germany) equipped with a Zeiss Axiocam MRc5 camera in was used in Innsbruck for examination of lipid staining (Sudan IV applied to razor blade-sectioned lyophilized field material) and investigation of semithin sections of fixed material (see below). Images were collected by Zeiss Axiovision software and further processed with Adobe Photoshop software.

\subsection{UV exposure and measurements}

Inside the $7{ }^{\circ} \mathrm{C}$ chamber, white fluorescent tubes (Osram, L65 Watt/25S, Munich, Germany) and UVA-340 fluorescent tubes (QPanel, Cleveland, OH, USA) were hanged above a shelf to provide
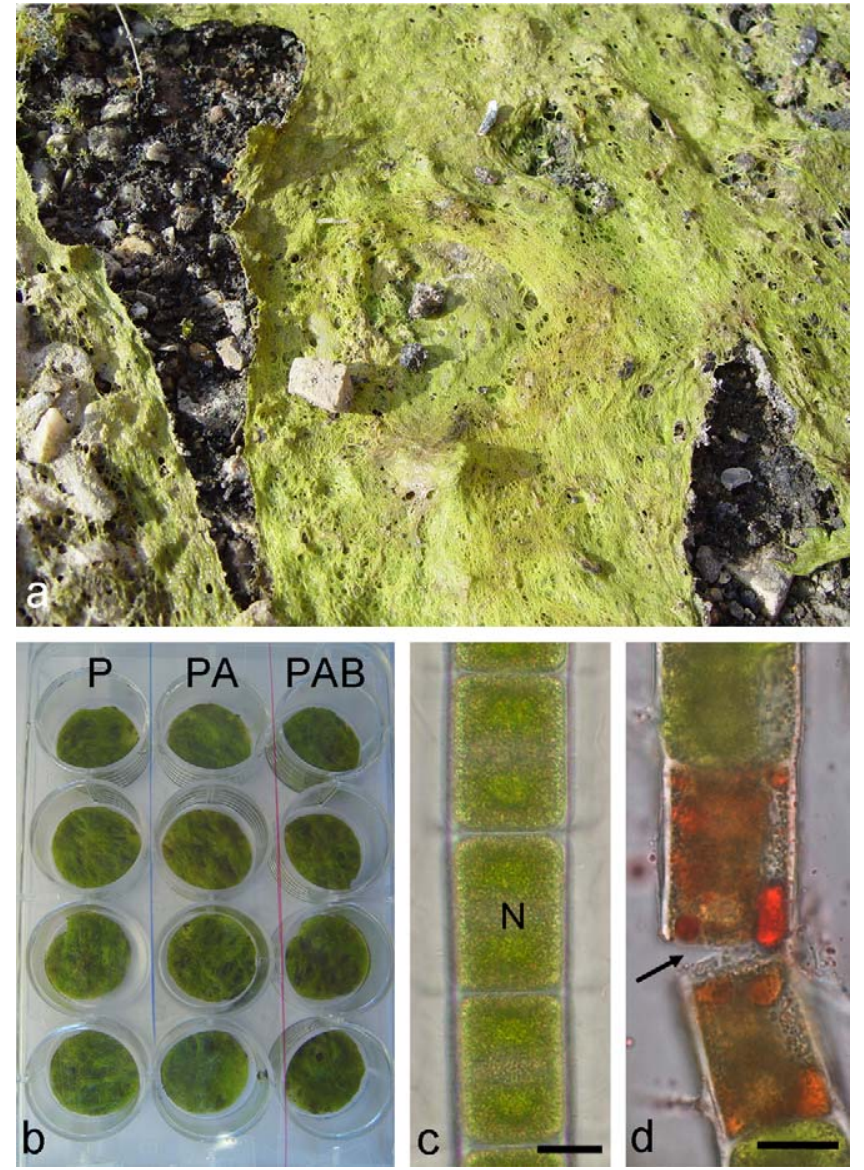

Fig. 1. Macroscopic and microscopic aspects of Zygnema sp. collected in a freshwater runlet in Ny-Ålesund, Spitsbergen. (a) Algal mats on their natural habitat, (b) 24 h exposure of cut out algal discs to P (first row, PAR), PA (second row, PAR + UV-A), PAB (third row, PAR + UV-A + UV-B), (c) light microscope image of field sample with nucleus $(\mathrm{N})$ in the center and two chloroplasts at the sides, (d) Sudan IV stained filament, mechanically opened (arrow), red lipid droplets. Bars (c and d) $20 \mu \mathrm{m}$.

photosynthetically active radiation (PAR, 400-700 nm) and ultraviolet radiation (UVR, $280-400 \mathrm{~nm}$ ), respectively. To cut off different wavelength ranges from the spectrum emitted by the fluorescent tubes, cell culture dishes were covered with one of the following filters: Ultraphan transparent (Digefra $\mathrm{GmbH}$, Munich, Germany); Folanorm (Folex GmbH, Dreieich, Germany) or Ultraphan URUV farblos (Digefra $\mathrm{GmbH}$, Munich, Germany) corresponding to the PAR + UV-A + UV-B (PAB, 280-700 nm), PAR + UV-A (PA, 320$700 \mathrm{~nm})$ and PAR (P, 400-700 nm) treatments, respectively. Ultraviolet radiation was measured using Solar Light PMA 2100 radiometer equipped with the UV-A sensor PMA 2110 and the UV-B Sensor PMA 2106 (Solar Light, Philadelphia, USA). Adjusted ultraviolet radiation below the cut-off filters was $4.00 \mathrm{~W} \mathrm{~m}^{-2}$ UV-A and $0.42 \mathrm{~W} \mathrm{~m}^{-2} \mathrm{UV}-\mathrm{B}$. The available PAR measured by a cosine quantum sensor attached to a LI-COR data logger (LI-1000, LI-COR Biosciences, Lincoln, Nebraska, USA) was $20 \mu \mathrm{mol}$ photons $\mathrm{m}^{-2} \mathrm{~s}^{-1}$ $\left(\sim 4.30 \mathrm{~W} \mathrm{~m}^{-2}\right)$. The maximum daily average irradiance in summer

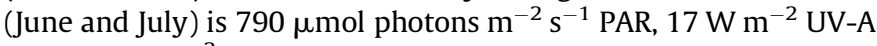
and $0.30 \mathrm{~W} \mathrm{~m}^{-2}$ UV-B in air (cf. Hanelt et al., 2001).

\subsection{Chlorophyll fluorescence measurements}

Photosynthetic activity was determined by measuring the variable chlorophyll (Chl) fluorescence of PS II. The effective quantum yield $\left(\Delta F / F_{\mathrm{m}}^{\prime}, n=3\right)$ and the rapid photosynthesis (in terms of relative electron transport rate, rETR $=\mathrm{PFR} \times \Delta F / F_{\mathrm{m}}^{\prime}$ ) 
versus irradiance $(E)$ curves ( $P-E$ curve) were measured in triplicates using a Maxi-Imaging Pulse Amplitude Modulation fluorometer (Imaging-PAM) connected to a PC operated with WinControl software (Heinz Walz GmbH, Effeltrich, Germany). $F_{\mathrm{o}}$ was measured with a blue measuring light pulse $(\sim 0.4 \mu \mathrm{mol}$ photon $\mathrm{m}^{-2} \mathrm{~s}^{-1}, 450 \mathrm{~nm}$ ), and $F_{\mathrm{m}}$ was determined with a $300 \mathrm{~ms}$ completely saturating white light pulse $(\sim 2000 \mu \mathrm{mol}$ photo$\mathrm{ns} \mathrm{m}^{-2} \mathrm{~s}^{-1}$ ). Actinic light intensities making up to 19 points (1$926 \mu \mathrm{mol}$ photons $\mathrm{m}^{-2} \mathrm{~s}^{-1}$ ) were used. The hyperbolic tangent model of Jassby and Platt (1976) was used to estimate $P-E$ curve parameters described as:

$\mathrm{rETR}=\mathrm{rETR}_{\max } \times \tanh \left(\alpha \times \mathrm{E}_{\mathrm{PAR}} \times \mathrm{rETR}_{\max }^{-1}\right)$

where $\mathrm{rETR}_{\max }$ is the maximum relative electron transport rate, tanh is the hyperbolic tangent function, $\alpha$ is the electron transport efficiency and $E$ is the photon fluence rate of PAR. Curve fit was calculated with the Solver Module of MS-Excel using the least squares method comparing differences between measured and calculated data. The saturation irradiance for electron transport $\left(E_{\mathrm{k}}\right)$ was calculated as the light intensity at which the initial slope of the curve $(\alpha)$ intercepts the horizontal asymptote $\left(\mathrm{rETR}_{\max }\right)$.

\subsection{Scanning electron microscopy}

Lyophilized field-collected samples of Zygnema sp. were mechanically cut and sputter-coated with gold-palladium and examined with a Philips XL20 scanning electron microscope (SEM) at $10 \mathrm{kV}$.

\subsection{Transmission electron microscopy}

Field-collected as well as $24 \mathrm{~h} \mathrm{P-,} \mathrm{PA-} \mathrm{and} \mathrm{PAB-treated} \mathrm{samples}$ of Zygnema sp. were fixed for transmission electron microscopy
(TEM) as described by Holzinger et al. (2006). Cells were fixed in $2.5 \%$ glutaraldehyde in $10 \mathrm{mM}$ cacodylate buffer ( $\mathrm{pH} \mathrm{6.8)}$ ) for $1 \mathrm{~h}$. After several rinsing steps, cells were post-fixed in $1 \% \mathrm{OsO}_{4}$ in the same buffer for $12 \mathrm{~h}$ at $4{ }^{\circ} \mathrm{C}$. After rinsing the cells were dehydrated in increasing ethanol concentrations, transferred to propylene oxide and embedded in low viscosity embedding resin (Agar Scientific, England). Semithin sections were stained with $0.3 \%$ Toluidine Blue $\mathrm{O}$ and examined at the light microscope to select reasonable cells for TEM observations. For TEM ultrathin $(\sim 60 \mathrm{~nm})$ sections were prepared with a Leica Ultracut, counterstained with aqueous uranyl acetate for $60 \mathrm{~min}$ and Reynold's lead citrate for $10 \mathrm{~min}$. Sections were examined with a Zeiss Libra $120 \mathrm{TEM}$ at 80 kV. Images were captured digitally with a ProScan 2k SSCCD camera, controlled with OSIS iTEM software and further processed with Adobe Photoshop software.

\section{Results}

\subsection{Microscopic aspects of Zygnema}

Under the light microscope, Zygnema cells measured a diameter of $\sim 32-34 \mu \mathrm{m}$ and were $\sim 1-1.5$ times longer as broad (Fig. $1 \mathrm{c}$ ). The nucleus was located in the center of the cell and two star-shaped chloroplasts were observed in each cell (Fig. 1c). The opaque appearance of the image was due to cytoplasmic components within the cell. Sudan IV stained cells gave a prominent staining of lipid bodies in mechanically ruptured cells (Fig. 1d).

\subsection{Physiological measurements}

No significant treatment effect (ANOVA, $P>0.05$ ) was observed in all measured and extrapolated $P-E$ curve parameters (Fig. 2,

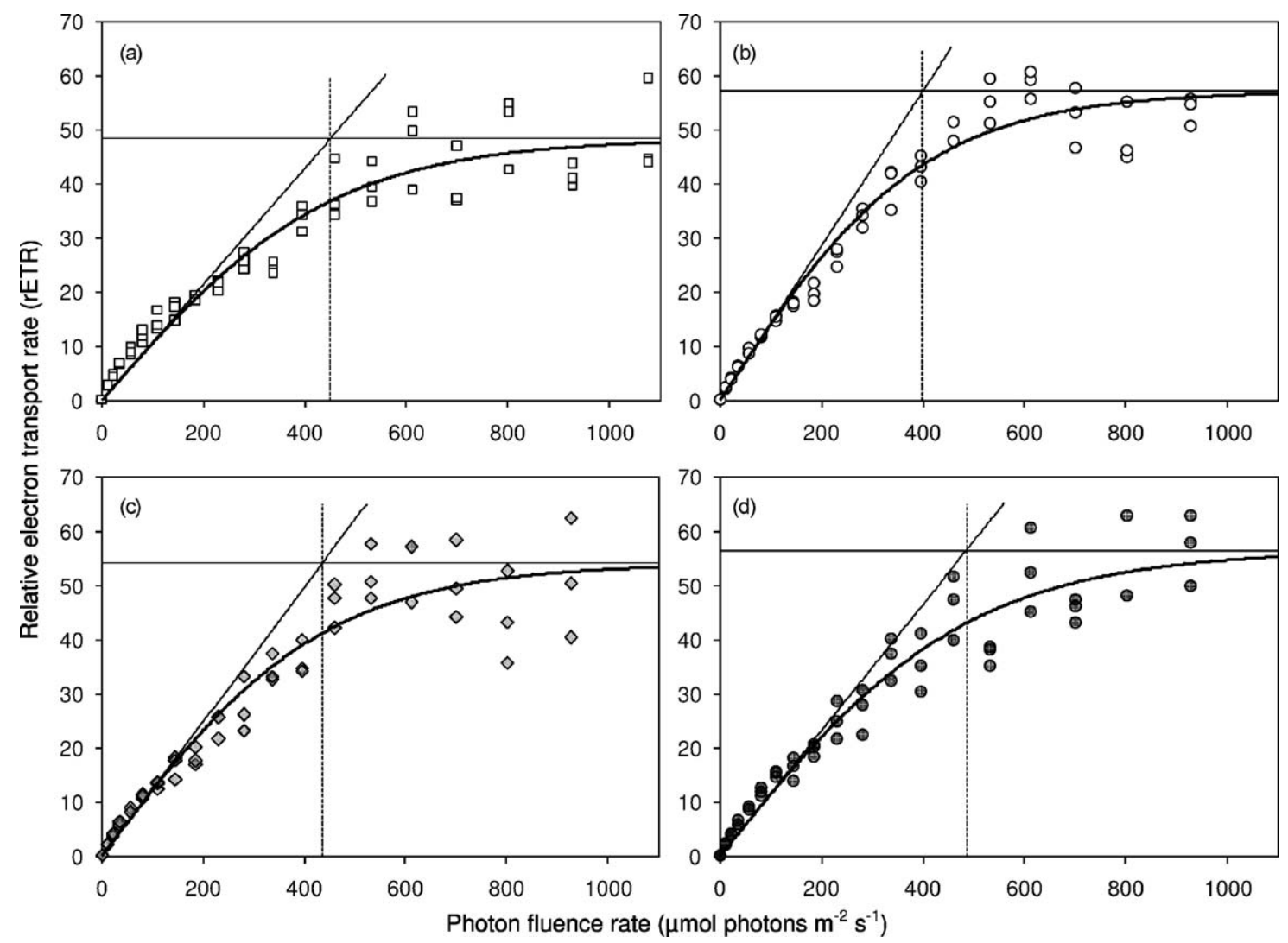

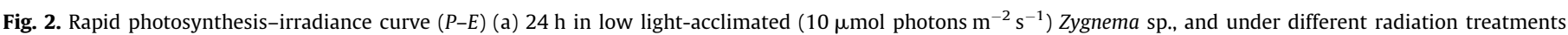

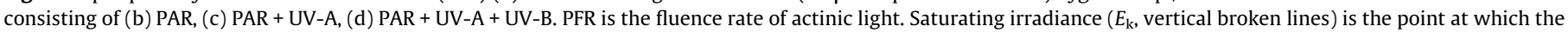
initial slope $(\alpha)$ crosses maximum photosynthesis $\left(\mathrm{rETR}_{\max }\right.$ ) using a hyperbolic tangent model. Parameter estimates are tabulated in Table 1. 
Table 1

Photosynthesis-irradiance $(P-E)$ curve parameters estimated using the hyperbolic tangent model of Jassby and Platt (1976). Saturating irradiance $\left(E_{\mathrm{k}}\right)$ is the light intensity (see Fig. 1) at which the initial slope of the curve $(\alpha)$ intercepts the horizontal asymptote, the maximum relative electron transport rate ( $\mathrm{rETR}_{\mathrm{max}}$ ). Analysis of variance showed no significant difference in parameter estimates between treatments.

\begin{tabular}{llll}
\hline Treatment & $E_{\mathrm{k}}\left(\mu \mathrm{mol}\right.$ photons $\left.\mathrm{m}^{-2} \mathrm{~s}^{-1}\right)$ & $\mathrm{rETR}_{\max }$ & Alpha \\
\hline Control & $450 \pm 109$ & $48.36 \pm 6.9$ & $0.107 \pm 0.01$ \\
P & $399 \pm 22$ & $57.08 \pm 2.0$ & $0.143 \pm 0.01$ \\
PA & $436 \pm 133$ & $54.09 \pm 9.3$ & $0.124 \pm 0.02$ \\
PAB & $486 \pm 154$ & $56.54 \pm 7.4$ & $0.116 \pm 0.02$ \\
\hline
\end{tabular}

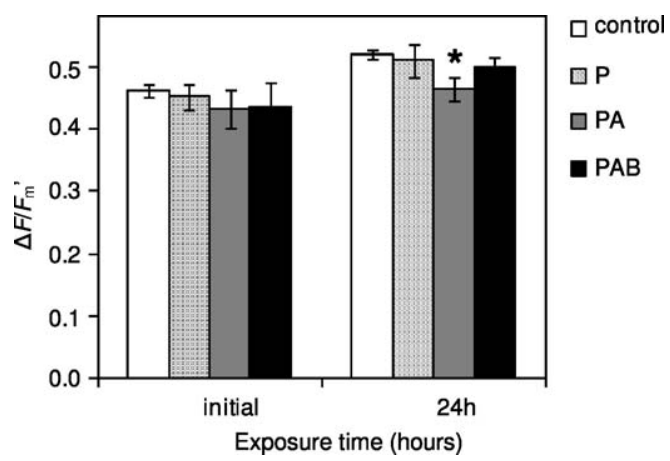

Fig. 3. Effective quantum yield $\left(\Delta F / F_{\mathrm{m}}^{\prime}\right)$ of Zygnema sp. mats exposed to artificial radiation. Radiation treatment consists of photosynthetically active radiation $(\mathrm{PAR}=\mathrm{P}), \mathrm{PAR}+\mathrm{UV}-\mathrm{A}(\mathrm{PA})$ and PAR + UV-A + UV-B (PAB). Artificial light photon flux density (PFD) is $20 \mu \mathrm{mol}$ photons $\mathrm{m}^{-2} \mathrm{~s}^{-1}$. Control (low PAR: $10 \mu \mathrm{mol}$ photons $\left.\mathrm{m}^{-2} \mathrm{~s}^{-1}\right)$. Vertical bars are standard deviations (SD, $\left.n=4\right)$. Analysis of variance $(P<0.01)$ and Duncan's multiple range test (DMRT, $P=0.05$ ) showed significantly lower $\Delta F / F_{\mathrm{m}}^{\prime}$ under PA $\left(^{*}\right)$ compared to other treatments.

Table 1). A relatively high photosynthetic capacity in terms of rETR $_{\max }$ with corresponding high saturating irradiance $\left(E_{\mathrm{k}}\right)$ was measured. No photoinhibition of photosynthesis was observed even at the highest actinic light treatment $(926 \mu \mathrm{mol}$ photo$\mathrm{ns} \mathrm{m}^{-2} \mathrm{~s}^{-1}$ ). The light harvesting performance and photosynthetic conversion efficiency $(\alpha)$ in filaments exposed to low light (control) was comparable to filaments exposed to the experimental radiation treatments ( $\mathrm{P}, \mathrm{PA}$ and $\mathrm{PAB})$.

Initial effective quantum yield $\left(\Delta F / F_{\mathrm{m}}^{\prime}\right.$, Fig. 3) of all independent experimental units $(n=4$ per treatment and laboratory control) measured a yield ranging from 0.387 to 0.476 rel. units. After $24 \mathrm{~h}$ exposure to artificial laboratory radiation, the yield increased by $10 \%$ with values ranging from 0.440 to 0.527 rel. units and a significant treatment effect was observed $(P=0.006)$. Post hoc Duncan's multiple range test (DMRT, $P=0.05$ ) showed lowest $\Delta F / F_{\mathrm{m}}^{\prime}$ in $\mathrm{PA}$, whereas $\mathrm{PAB}, \mathrm{P}$ and the control are not significantly different (Fig. 3).

\subsection{Visualization of cellular contents}

Toluidine Blue $\mathrm{O}$ stained semithin sections of fixed and embedded field-collected (not shown) and $24 \mathrm{~h} P$ exposed samples showed numerous brownish lipid bodies in the cytoplasm (Fig. 4a). In addition, blue-stained bodies, representing acidic polysaccharides, were observed in the same area (Fig. 4a). Similar images were obtained when Zygnema sp. was exposed for $24 \mathrm{~h}$ to PA (not shown) and PAB (Fig. 4b). Occasionally an accumulation of the blue-stained bodies to one side of the filament was observed, but we did not see any obvious difference in the number of these particles in relation to the different light exposures or the field control. In scanning electron micrographs of dissected cells, a granular content, representing lipid bodies was visible (Fig. 4c).
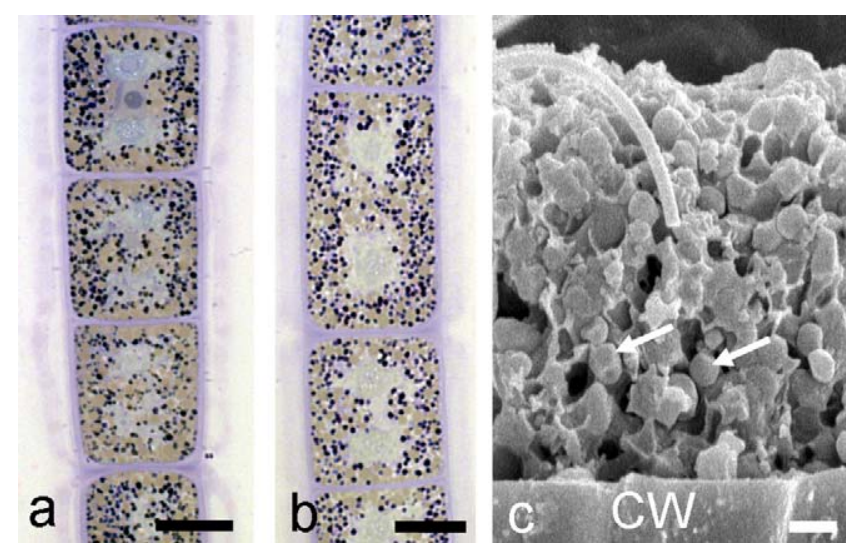

Fig. 4. Semithin sections of fixed Zygnema sp. (a and b) and scanning electron micrograph of Zygnema sp. of freeze-dried filed sample (c). (a) Sample exposed to PAR (P), (b) sample exposed to PAR + UV-A + UV-B (PAB), and (c) contents of mechanically opened filament, round structures likely represent lipid bodies (arrows), cell wall at the bottom (CW); Bars (a and b) $20 \mu \mathrm{m}$; (c) $2 \mu \mathrm{m}$.

\subsection{Transmission electron microscopy}

Field samples of Zygnema, regarded as field control showed multi-lobed chloroplasts in the central parts of the cells surrounded by electron opaque ("grey") lipid bodies with diameters of up to 2$3 \mu \mathrm{m}$ and electron dense particles with a diameter of $\sim 1 \mu \mathrm{m}$ (Fig. 5a). The thylakoid membranes sometimes appeared irregular or slightly dilated and contained numerous plastoglobules with an average diameter of $\sim 200-250 \mathrm{~nm}$ (Fig. 5b). Next to the chloroplast mitochondria were observed (Fig. 5c). The cell wall had a homogenous appearance and was $\sim 2 \mu \mathrm{m}$ thick (Fig. 5d). Similar images were obtained when $24 \mathrm{~h} \mathrm{P}$ exposed cells, regarded as laboratory control, were investigated. The nucleus was located in the center of the cell (Fig. 5e), surrounded by the chloroplasts. Golgi bodies with $\sim 10$ cisternae were seen close to chloroplast lobes (Fig. 5f). In P exposed Zygnema cells, again numerous lipid bodies were observed in the cytoplasm (Fig. 5e). In addition, electron dense particles were observed (Fig. 5e). Within the cytoplasm several Golgi bodies with an average of $\sim 10$ cisternae were found (Fig. 5f). The thylakoid membranes had an irregular appearance, and smaller electron dense spots ( $\sim 70 \mathrm{~nm}$ ) were observed at the margins of the thylakoid membranes (Fig. 5f).

The ultrastructure of Zygnema under PA-exposure remains unaffected (Fig. 6a-c). The nucleus in the cell center was surrounded by the chloroplasts, holding pyrenoids with numerous starch granules (Fig. 6a). The chloroplasts contained substantial amounts of plastoglobules (Fig. 6b) and the thylakoid membranes appeared dilated in some parts of the chloroplast (Fig. 6b). Other organelles like mitochondria or Golgi bodies had a similar appearance as in control cells. In the cell cortex, a dense accumulation of lipid bodies and irregularly shaped electron dense particles was observed (Fig. 6c). The ultrastructure of Zygnema was also not compromised under PAB treatment (Fig. 6d). The chloroplasts with pyrenoids contained starch grains (Fig. 6d). Lipid bodies and electron dense particles were viewed in the cortex and the central cytoplasm. Golgi bodies did not seem to be affected by PAB (Fig. 6d).

\section{Discussion}

The Zygnema isolate from Spitsbergen is well adapted to the harsh arctic environment exposed to a long period of freezing temperatures, periodic desiccation and high UV radiation during polar days. Photosynthesis of Zygnema mats exposed to high UVR:PAR ratio in the laboratory was not impaired. Ultrastructure 

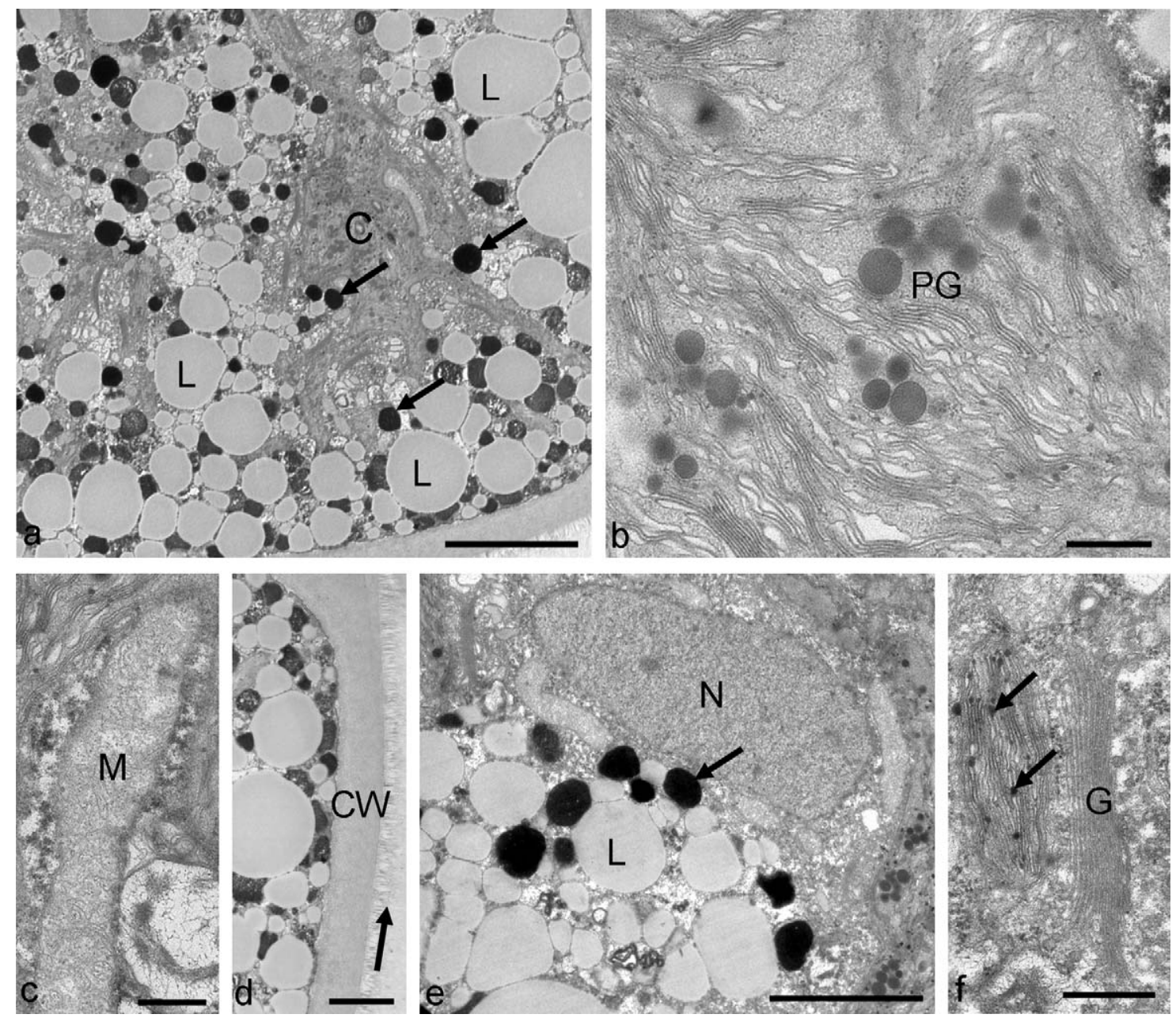

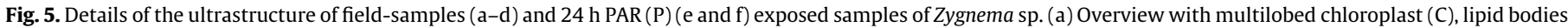

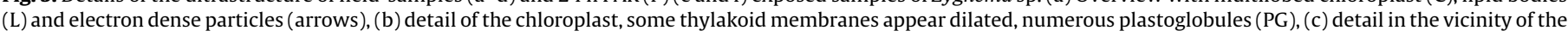

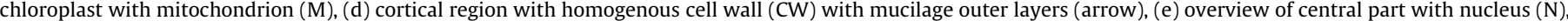

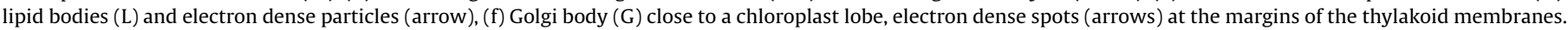
Bars (a, d and e) $2 \mu \mathrm{m}$; (b, c and f) $500 \mathrm{~nm}$.

analysis of field samples and samples exposed to P, PA, PAB regimes in the laboratory did not show any significant alteration.

Previously, Antarctic Zygnema sp. is reported to be resilient to repeated freeze-thaw cycles between 5 and $-4{ }^{\circ} \mathrm{C}$ without physiological consequence on their photosynthetic capacity (Hawes, 1990). Zygnema is capable of forming "akinetes", persisting vegetative stages that are able to sustain unfavorable environmental conditions (McLean and Pessoney, 1971). This, however was not observed in the Zygnema isolate from Spitsbergen.

Despite the experimental limitation to simulate the PAR/UVR ratio as in the field (which would require a very difficult technical setup), the relatively higher input of short-wave irradiation to PAR (high UVR:PAR ratio) did not show significant effects on the $P-E$ curve parameters and on the photoinhibition of PSII quantum yield. This indicates that Zygnema, exposed to rather high solar radiation, is well adapted to their growth conditions and shows enough plasticity to cope with higher loads of short-wave irradiation in the laboratory. Prolonged and repeated daily exposure to experimental light treatment in the laboratory (e.g. Gao et al., 2009) will most likely not change the sensitivity of Zygnema to UVR. The effect of UVR on photosynthesis is observed immediately. For example, Urospora filaments exposed to comparable irradiance was already photoinhibited after $1 \mathrm{~h}$ and $\Delta F / F_{\mathrm{m}}^{\prime}$ continuously decrease up to the maximum $16 \mathrm{~h}$ UVR treatment (Roleda et al., 2009a,b). Zygnema seems to have a better photoprotective mechanism compared to an Arctic green macroalga Urospora inhabiting the upper eulittoral zone where its $E_{\mathrm{k}}$, $\mathrm{rETR}_{\max }$ and $\alpha$ were significantly affected under UVR (Roleda et al., 2009b).

The high $E_{\mathrm{k}}$ values (399-486 $\mu \mathrm{mol}$ photons $\mathrm{m}^{-2} \mathrm{~s}^{-1}$ ) measured in this study imply that the solar radiation-exposed Zygnema is sunadapted. Higher saturating irradiance was observed in snow algae Chlamydomonas nivalis $\left(E_{\mathrm{k}}=523-826 \mu \mathrm{mol}\right.$ photons $\left.\mathrm{m}^{-2} \mathrm{~s}^{-1}\right)$ inhabiting snow surface with very high irradiation intensities (Stibal et al., 2007). Relatively higher $E_{\mathrm{k}}$ value was measured in Antarctic Urospora $\left(E_{\mathrm{k}}=252 \mu \mathrm{mol}\right.$ photons $\mathrm{m}^{-2} \mathrm{~s}^{-1}$; Roleda et al., 2009a) compared to high Arctic Urospora $\left(E_{\mathrm{k}}=82 \mu \mathrm{mol}\right.$ photons $\mathrm{m}^{-2} \mathrm{~s}^{-1}$; Roleda et al., 2009b). This can be attributed to the higher solar radiation encountered by eulittoral macroalgae during austral spring in Antarctica, with sampling sites at lower latitude $\left(\sim 62^{\circ} \mathrm{S}\right)$. In the Arctic Prasiola crispa, growing in similar habitats as the here investigated Zygnema, $E_{\mathrm{k}}$ values of $\sim 30 \mu \mathrm{mol}$ photons $\mathrm{m}^{-2} \mathrm{~s}^{-1}$ were measured in control and UVR exposed samples (Holzinger et al., 2006). In the laboratory, increasing culture light regime from 75 to $300 \mu \mathrm{mol}$ photons $\mathrm{m}^{-2} \mathrm{~s}^{-1}$ PAR yielded a corresponding increase in the $E_{\mathrm{k}}$ of the summer bloom-forming cyanobacteria Nodularia spumigena from 18 to $190 \mu \mathrm{mol}$ photons $\mathrm{m}^{-2} \mathrm{~s}^{-1}$, respectively (Roleda et al., 2008). Exposure to ambient solar radiation can potentially increase the $E_{\mathrm{k}}$ of $N$. spumigena comparable to that of Zygnema sp. and C. nivalis. In any case, the rather high $E_{\mathrm{k}}$ values of 

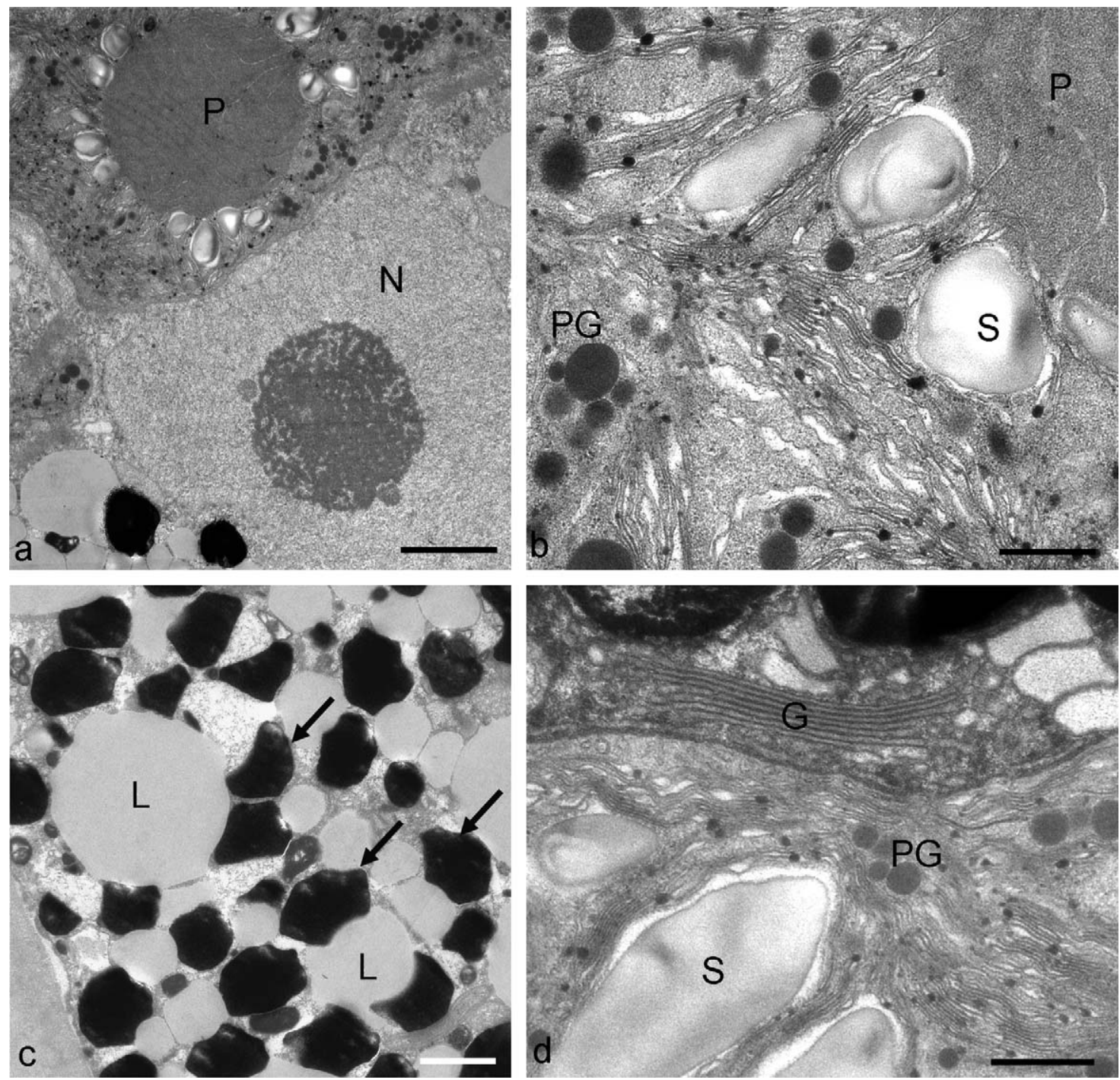

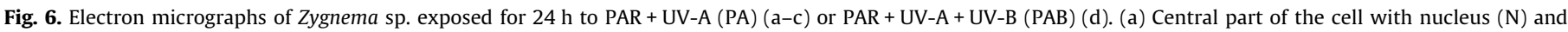

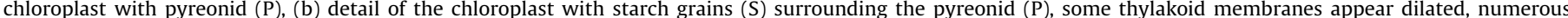

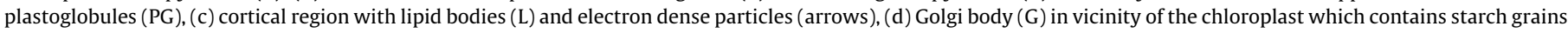
(S) and plastoglobules (PG). Bars (a) $2 \mu \mathrm{m}$; (c) $1 \mu \mathrm{m}$; (b and d) $500 \mathrm{~nm}$.

Zygnema are astonishing for an organism that is naturally exposed to a maximum photon fluence rate of $1300 \mu \mathrm{mol}$ photons $\mathrm{m}^{-2} \mathrm{~s}^{-1}$ (see Bischof et al., 1998 on maximum ambient PAR).

The overall good performance of Zygnema can also be attributed to mat formation consisting of layers up to several $\mathrm{mm}$ thick where the upper filaments in the layer may protect the filaments in deeper layers. Therefore we cannot exclude the possibility that the high $E_{\mathrm{k}}$ values detected in Zygnema could be caused by the multi-layers of filaments in the mats. Irradiation of these multi-layers with increasing radiation could yield a mixed signal originating from filaments at different vertical positions, which exhibit different degrees of photoacclimation by selfshading. A similar phenomenon has been observed in Ulva, where layers of thalli piling on top of each forming mat-like canopies. The upper layers are bleached and acted as an UV-B filter protecting the lower layers from harmful irradiation (Bischof et al., 2002). The upper layers of Zygnema mat were, however, not substantially bleached.

Under laboratory condition, the experimental PAR used ( $20 \mu \mathrm{mol}$ photons $\mathrm{m}^{-2} \mathrm{~s}^{-1}$ ) was very low compared to PAR irradiance in their habitat. Among plants exposed to low PAR supplemented with UVR, the high UVR:PAR ratio in the laboratory is suggested to exaggerate UVR effects on photosynthesis (Fredersdorf and Bischof, 2007; Hanelt and Roleda, 2009). This was, however, not observed in this study. Remarkably, a significantly lower $\Delta F / F_{\mathrm{m}}^{\prime}$ in plants exposed to PAR supplemented with UV-A (PA) compared to plants exposed to the whole radiation spectra (PAB) and PAR-only treatment was observed. UV-A irradiation is reported to be damaging for PSII, affecting electron transport at the water-oxidizing complex and the binding site of the $\mathrm{Q}_{\mathrm{B}}$ quinine electron acceptor (Turcsányi and Vass, 2000). UV-A can also damage the catalytic manganese cluster of the wateroxidizing complex (Vass et al., 2002). This damaging mechanism is similar to that induced by the shorter UV-B $(280-320 \mathrm{~nm})$ radiation, but different from that induced by the longer wavelength PAR (400-700 nm, Vass et al., 2002). Generally, the UV-B waveband is only regarded as damaging. At ecologically relevant irradiance, UV-B may function as a photoreceptor signal necessary for recovery process in plants adapted to a high UVenvironment (cf. Flores-Moya et al., 1999; Sicora et al., 2003; Hanelt and Roleda, 2009; Hanelt et al., 2006). Plants growing in low ambient irradiance habitats are usually most sensitive to UVR as exemplified by the deep water macroalgae and their propagules. Consequently, numerous studies have also shown that recovery 
from photoinhibition is delayed after exposure to additional UV irradiation (e.g. Roleda, 2009; Roleda et al., 2006a).

Lipids have been detected in Sudan IV-stained Zygnema viewed by light microscopy. This was confirmed in the ultrastructure seen as electron opaque ("grey") bodies in all samples examined by TEM. The amount of lipid bodies, filling most of the cytoplasm in Zygnema is surprising. The presence of oil droplets was recently described in arctic Zygnema examined microscopically (Kim et al., 2008). Previous reports on the ultrastructure of cultured (at moderate temperatures) Zygnema did not show lipid accumulations, while the cell cortex was filled with vacuoles (Bakker and Lokhorst, 1987; McLean and Pessoney, 1971).

It is often observed that under nitrogen limitation, lipids are synthesized in algae, because other pathways to form proteincontaining cell structures are suppressed. Lipid accumulations are observed when algae are subjected to unfavorable culture conditions or stressed, such as nutrient starvation, photo-oxidative stress, desiccation or cold treatment (Hu et al., 2008; Rodolfi et al., 2008; Holzinger, 2009). An extensive occurrence of lipid bodies was observed in Prasiola crispa when exposed to experimental UVR dose in the laboratory (Holzinger et al., 2006) or salinity changes and desiccation (Jacob et al., 1992a,b). Lipid storage in Ulva also increased with increasing light intensity (Khotimchenko and Yakovleva, 2004). Moreover, the fatty acid composition in Antarctic green algae changes with culture temperatures (Teoh et al., 2004).

In contrast, examination in Zygogonium ericetorum, collected in an high alpine habitat exposed to higher UV load compared to Spitsbergen, showed numerous vacuoles and virtually no lipid bodies in the cytoplasm of field-collected samples (Holzinger et al., 2009). Although both, Zygnema and Zygogonium belong to the Zygnematales, there is a strong indication of a species-specific biochemical response to UVR, or the synergistic effects of different environmental variables operating in the high alpine habitat compared to the arctic induces different biochemical pathways. Organelles like Golgi bodies or mitochondria did not seem to be influenced by the experimental UV irradiation. The slightly dilated thylakoid membranes were also observed in field-control samples and $24 \mathrm{~h}$ P-exposed samples and could therefore not be regarded as an UVR effect. Moreover, similar quantities of plastoglobules were observed in control as well as UVR-exposed samples. The special cubic-membraned structures in the chloroplasts previously observed by McLean and Pessoney (1970) and Deng and Landh (1995) in Zygnema was not observed in this study.

As recently reported, the ultrastructure of the green alga Urospora is similarly insensitive to experimental UVR (Roleda et al., 2009b). In Urospora, an evident increase in electron dense bodies in the cytoplasm was observed under UVR. Similar dark particles have been observed in Zygnema, but no apparent increase was observed under similar UVR irradiance and higher UVR dose. Although, similar structures are frequently observed in green algae (e.g. Holzinger and Lütz, 2006; Remias et al., 2005, 2009), the significance of the prominent occurrence of the electron dense bodies in the cytoplasm of Zygnema remained unclear.

Green algae like Micrasterias (desmids) were able to withstand harsh experimental UVR treatments, and only wavelengths lower than $284 \mathrm{~nm}$ have been reported to induce changes in the ultrastructure (Meindl and Lütz, 1996; Lütz et al., 1997). In desmids, the production of vast amounts of slime may elicit protective function leading to UV tolerance, although UV screening compounds have so far not been detected in the mucilage.

The effects of UVR on the ultrastructure in algae have been summarized by Holzinger and Lütz (2006). The overall good performance and higher tolerance of green algae (e.g. Holzinger et al., 2006; Roleda et al., 2009a,b) are in strong contrast to observations in marine red macroalgae (e.g. Holzinger et al., 2004;
Poppe et al., 2002, 2003) and some brown algae (e.g. Roleda et al., 2006b; Steinhoff et al., 2008). This is not only related to their growth habit with different micro-climate at different depths but also related to their phylogeny with distinct biochemical pathways and physiological response and tolerance to different stress factors.

In summary, we observed that the Arctic Zygnema isolate is well adapted to the extreme environment. A previously collected Zygnema isolate from Ny-Ålesund is stenothermic (survives only at $<10^{\circ} \mathrm{C}$, Kim et al., 2008). Certain genetically-fixed physiological protective mechanism could be operating in this species responsible for their ecological success in extreme Arctic environmental condition. Biochemical mechanisms of cellular protection in terms of low molecular solutes production for freezing point depression should be examined.

Few tundra algal species undergo sexual reproduction to form resistant spores for over-wintering (Prescott, 1963; Sheath and Steinman, 1982). Consequently, the occurrence of vegetative-only population of Zygnema in Spitsbergen and the apparent loss of sexual phase (cf. Kim et al., 2008) suggest a trade-off between sexual reproduction and survival in extreme environment. When sexual recruitment in Arctic Zygnema was environmentally suppressed, natural selection eliminates the traits involved in sex (cf. Eckert, 2002) that may have facilitated the evolution of genetically distinct vegetative-only populations. Morphologically, filaments of different isolates of Zygnema looked similar in the light microscope. Molecular taxonomic approaches such as $18 \mathrm{~S}$ and ITS rDNA sequencing will determine the relatedness of the different isolates of Zygnema to explain their phylogeny and relative resilience to different environmental factors in general and to UVR in particular.

\section{Conflict of interest}

The authors declare that they have no conflict of interest.

\section{Acknowledgements}

We are indebted to Prof. C. Wiencke, Alfred Wegener Institute for Polar and Marine Research, Bermerhaven, Germany for using equipment in the Marine Biology Lab in Ny-Ålesund. Moreover, we thank W. Kofler, University of Innsbruck, Austria for expert technical assistance in performing SEM. This research was supported by the Austrian Science Fund (FWF) grant ZFP 200810 to C.L.

\section{References}

Bakker, M.E., Lokhorst, G.M., 1987. Ultrastructure of mitosis and cytokinesis in Zygnema sp. (Zygnematales, Chlorophyta). Protoplasma 138, 105-118.

Billingham, M.R., Reusch, T.B.H., Alberto, F., Serrão, E.A., 2003. Is asexual reproduction more important at geographical limits? A genetic study of the seagrass Zostera marina in the Ria Formosa, Portugal. Mar. Ecol. Prog. Ser. 265, 77-83.

Bischof, K., Gloria Peralta, G., Kräbs, G., van de Poll, W.H., Pérez-Lloréns, J.L., Breeman, A.M., 2002. Effects of solar UV-B radiation on canopy structure of Ulva communities from southern Spain. J. Exp. Bot. 53, 2411-2421.

Bischof, K., Hanelt, D., Karsten, U., Brouwer, P., Tüg, H., Wiencke, C., 1998. Acclimation of brown algal photosynthesis to ultraviolet radiation in Arctic coastal waters (Spitsbergen, Norway). Polar Biol. 20, 388-395.

Björn, L.O., 2002. Effects of ultraviolet-B radiation on terrestrial organisms and ecosystems. In: Hessen, D.O. (Ed.), UV Radiation and Arctic Ecosystems. Ecological Studies 153. Springer Verlag, Berlin, Heidelberg, pp. 93-121.

Björn, L.O., 2008. Photobiology-The Science of Life and Light, 2nd ed. Springer Science and Business Media, LLC, New York, USA.

Björn, L.O., Callaghan, T.V., Gehrke, C., Johanson, U., Sonesson, M., 1999. Ozone depletion, ultraviolet radiation and plant life. Chemosphere: Global Change Sci. $1,449-454$

Brook, A.J., Johnson, L.R., 2002. Order Zygnematales. In: John, D.M., Whitton, B.A., Brook, A.J. (Eds.), The Freshwater Algal Flora of the British Isles. Cambridge University Press, Cambridge, UK, pp. 479-593.

Caldwell, M.M., Björn, L.O., Bornman, J.F., Flint, S.D., Kulandaivelu, G., Teramura, A.H., Tevini, M., 1998. Effects of increased solar ultraviolet radiation on terrestrial ecosystems. J. Photochem. Photobiol. 46, 40-52. 
Cordi, B., Donkin, M.E., Peloquin, J., Price, D.N., Depledge, M.H., 2001. The influence of UV-B radiation on the reproductive cells of the intertidal macroalga, Enteromorpha intestinalis. Aquat. Toxicol. 56, 1-11.

Dahlback, A., 2002. Recent changes in surface ultraviolet solar radiation and stratospheric ozone at a high arctic site. In: Hessen, D.O. (Ed.), UV Radiation and Arctic Ecosystems. Ecological Studies 153. Springer Verlag, Berlin, Heidelberg, pp. 322.

Deng, Y., Landh, T., 1995. The cubic gyroid-based membrane structure of the chloroplast in the Zygnema (Chlorophyceae Zygnematales). Zool. Stud. 34 (Suppl. 1), 175-177.

Eckert, C.G., 2002. The loss of sex in clonal plants. Evol. Ecol. 15, 501-520.

Elster, J., 2002. Ecological classification of terrestrial algal communities in polar environments. In: Beyer, L., Bölter, M. (Eds.), Geoecology of Antarctic Ice-Free Costal Landscapes. Ecologial Studies 154. Springer, Berlin, Heidelberg, pp. 303326.

Fahey, D.W., 2003. Twenty Questions and Answers About the Ozone Layer: Scientific Assessment of Ozone Depletion: 2002. World Meteorological Organization, Geneva.

Flores-Moya, A., Hanelt, D., Lopez-Figueroa, F., Altamirano, M., Viñegla, B., Salles, S., 1999. Solar UV-B radiation shows beneficial effects on recovery of inhibited photosynthesis in the brown alga Dictyota dichotoma. J. Photochem. Photobiol. B 49, 129-135.

Fredersdorf, J., Bischof, K., 2007. Irradiance of photosynthetically active radiation determines ultraviolet-susceptibility of photosynthesis in Ulva lactuca L. (Chlorophyta). Phycol. Res. 55, 295-301.

Gao, G., Gao, K., Giordano, M., 2009. Responses to solar UV radiation of the diatom Skeletonema costatum (Bacillariophyceae) grown at different $\mathrm{Zn}^{2+}$ concentrations. J. Phycol. 45, 119-129.

Hanelt, D., Hawes, I., Rae, R., 2006. Reduction of UV-B radiation causes an enhancement of photoinhibition in high light stressed aquatic plants from New Zealand lakes. J. Photochem. Photobiol. B 84, 89-102.

Hanelt, D., Roleda, M.Y., 2009. UVB radiation may ameliorate photoinhibition in specific shallow-water tropical marine macrophytes. Aquat. Bot. 91, 6-12.

Hanelt, D., Tüg, H., Bischof, K., Groß, C., Lippert, H., Sawall, T., Wiencke, C., 2001. Light regime in an arctic fjord: a study related to stratospheric ozone depletion as a basis for determination of UV effects on algal growth. Mar. Biol. 138, 649658.

Hawes, I., 1990. Effects of freezing and thawing on a species of Zygnema (Chlorophyta) from Antarctica. Phycologia 29, 326-331.

Helbling, E.W., Villafane, V.E., Buma, A.G.J., Andrade, M., Zaratti, F., 2001. DNA damage and photosynthetic inhibition induced by solar ultraviolet radiation in tropical phytoplankton (Lake Titicaca, Bolivia). Eur. J. Phycol. 36, 157-166.

Hessen, D.O., 2002. UV Radiation and Arctic Ecosystems. Ecological Studies 153. Springer Verlag, Berlin, Heidelberg, Germany, 321 p.

Holzinger, A., 2009. Desiccation tolerance in green algae: Implications of physiological adaptation and structural requirements. In: Hagen, K.N. (Ed.), Algae: Nutrition, Pollution Control and Energy Sources. Nova Science Publishers, Hauppauge, NY, pp. 41-56.

Holzinger, A., Karsten, U., Lütz, C., Wiencke, C., 2006. Ultrastructure and photosynthesis in the supralittoral green macroalga Prasiola crispa (Lightfoot) Kützing from Spitsbergen (Norway) under UV exposure. Phycologia 45, 168-177.

Holzinger, A., Lütz, C., 2006. Algae and UV irradiation: effects on ultrastructure and related metabolic functions. Micron 37, 190-207.

Holzinger, A., Lütz, C., Karsten, U., Wiencke, C., 2004. The effect of ultraviolet radiation on ultrastructure and photosynthesis in the red macroalgae Palmaria palmata and Odonthalia dentata from Arctic waters. Plant Biol. 6, 568-577.

Holzinger, A., Tschaikner, A., Remias, D., 2009. Cytoarchitecture of the desiccationtolerant green alga Zygogonium ericetorum. Protoplasma, doi:10.1007/s00709009-0048-5.

Hu, Q., Sommerfeld, M., Jarvis, E., Ghirardi, M., Posewitz, M., Seibert, M., Darzins, A., 2008. Microalgal triacylglycerols as feedstocks for biofuel production: perspectives and advances. Plant J. 54, 621-639.

Jacob, A., Lehmann, H., Kirst, G.O., Wiencke, C., 1992a. Changes in the ultrastructure of Prasiola crispa ssp. antarctica under salinity stress. Bot. Acta 105, 41-46.

Jacob, A., Wiencke, C., Lehmann, H., Kirst, G.O., 1992b. Physiology and ultrastructure of desiccation in the green alga Prasiola crispa from Antarctica. Bot. Mar. 35, 297-303.

Jassby, A.D., Platt, T., 1976. Mathematical formulation of the relationship between photosynthesis and light for phytoplankton. Limnol. Oceanogr. 21, 540-547.

Jin, J.J., Semeniuk, K., Manney, G.L., Jonsson, A.I., Beagley, S.R., McConnell, J.C., Dufour, G., Nassar, R., Boone, C.D., Walker, K.A., Bernath, P.F., Rinsland, C.P., 2006. Severe Arctic ozone loss in the winter 2004/2005: observations from ACEFTS. Geophys. Res. Lett. 33, L15801, doi:10.1029/2006GL026752.

Kearney, M.R., 2003. Why is sex so unpopular in the Australian desert? Trends Ecol. Evol. 18, 605-607.

Khotimchenko, S.V., Yakovleva, I.M., 2004. Effect of solar irradiance on lipids of the green alga Ulva fenestrata Postels et Ruprecht. Bot. Mar. 47, 395-401.

Kim, G.H., Klochkova, T.A., Kang, S.H., 2008. Notes on freshwater and terrestrial algae from Ny-Ålesund, Svalbard (high Arctic sea area). J. Environ. Biol. 29, 485491.

Komulayanen, S.F., 2008. Green algae as a structural element of phytoperiphyton communities in streams of NW Russia. Biologia 63, 859-865.
Lütz, C., Seidlitz, H.K., Meindl, U., 1997. Physiological and structural changes in the chloroplast of the green alga Micrasterias denticulata induced by UV-B simulation. Plant Ecol. 128, 54-64.

McLean, R.J., Pessoney, G.F., 1970. A large scale quasi-crystalline lamellar lattice in chloroplasts of the green alga Zygnema. J. Cell Biol. 45, 522-531.

McLean, R.J., Pessoney, F., 1971. Formation and resistance of akinetes of Zygnema. In: Parkaer, B.C., Brown, Jr., R.M. (Eds.), Contributions in Phycology. Allen Press, Lawrence, Kansas, USA, pp. 145-152.

Meindl, U., Lütz, C., 1996. Effects of UV irradiation on cell development and ultrastructure of the green alga Micrasterias. J. Photochem. Photobiol. B 36, 285-292.

Muscari, G., di Sarra, A.G., de Zafra, R.L., Lucci, F., Baordo, F., Angelini, F., Fiocco, G. 2007. Middle atmospheric $\mathrm{O}_{3}, \mathrm{CO}, \mathrm{N}_{2} \mathrm{O}, \mathrm{HNO}_{3}$, and temperature profiles during the warm Arctic winter 2001-2002. J. Geophys. Res. [Atmos.] 112, D14304, doi:10.1029/2006JD7849.

Peck, J.R., Yearsley, J.M., Waxman, D., 1998. Explaining the geographic distribution of sexual and asexual populations. Nature 391, 889-892.

Poppe, F., Hanelt, D., Wiencke, C., 2002. Changes in ultrastructure, photosynthetic activity and pigments in the Antarctic red alga Palmaria decipiens during acclimation to UV radiation. Bot. Mar. 45, 253-261.

Poppe, F., Schmidt, R.A.M., Hanelt, D., Wiencke, C., 2003. Effects of UV radiation on the ultrastructure of several red algae. Phycol. Res. 51, 11-19.

Poulíčková, A., Hašler, P., Lysáková, M., Spears, B., 2008. The ecology of freshwater epipelic algae: an update. Phycologia 47, 437-450.

Prescott, G.W., 1963. Ecology of Alaskan freshwater algae. II. Introduction: general considerations. Trans. Am. Microsc. Soc. 82, 83-142.

Remias, D., Holzinger, A., Lütz, C., 2009. Ultrastructure and physiological characterization of the ice alga Mesotaenium berggrenii (Zygnemaphyceae, Chlorophyta) from glaciers in the European alps. Phycologia, 48, 302-312.

Remias, D., Lütz-Meindl, U., Lütz, C., 2005. Photosythesis, pigments and ultrastructure of the alpine snow alga Chlamydomonas nivalis. Eur. J. Phycol. 40, 259-268.

Rodolfi, L., Zittelli, G.C., Bassi, N., Padovani, G., Biondi, N., Bovini, G., Tredici, M.R., 2008 Microalgae for oil: strain selection, induction of lipid synthesis and outdoor mass cultivation in a low-cost photobioreactor. Biotechnol. Bioeng. 102, 100-112.

Roleda, M.Y., 2009. Photosynthetic response of Arctic kelp zoospores exposed to radiation and thermal stress. Photochem. Photobiol. Sci., doi:10.1039/ B901098J.

Roleda, M.Y., Campana, G.L., Wiencke, C., Hanelt, D., Quartino, M.L., Wulff, A., 2009a. Sensitivity of Antarctic Urospora penicilliformis (Ulotrichales, Chlorophyta) to ultraviolet radiation is life stage dependent. J. Phycol. 45, 600-609.

Roleda, M.Y., Hanelt, D., Wiencke, C., 2006a. Exposure to ultraviolet radiation delays photosynthetic recovery in Arctic kelp zoospores. Photosynth. Res. 88, 311-322.

Roleda, M.Y., Lütz-Meindl, U., Wiencke, C., Lütz, C., 2009b. Physiological, biochemical, and ultrastructural responses of the green macroalga Urospora penicilliformis from Arctic Spitsbergen to UV radiation. Protoplasma, doi:10.1007/ s00709-009-0037-8.

Roleda, M.Y., Mohlin, M., Pattanaik, B., Wulff, A., 2008. Photosynthetic response of Nodularia spumigena to UV and photosynthetically active radiation depends on nutrient ( $\mathrm{N}$ and $\mathrm{P}$ ) availability. FEMS Microbiol. Ecol. 66, 230-242.

Roleda, M.Y., Wiencke, C., Hanelt, D., Bischof, K., 2007. Sensitivity of the early life stages of macroalgae from the Northern Hemisphere to ultraviolet radiation. Photochem. Photobiol. 83, 851-862.

Roleda, M.Y., Wiencke, C., Lüder, U.H., 2006b. Impact of ultraviolet radiation on cell structure, UV-absorbing compounds, photosynthesis, DNA damage, and germination in zoospores of Arctic Saccorhiza dermatodea. J. Exp. Bot. 57, 3847-3856.

Sheath, R.G., Steinman, A.D., 1982. A checklist of freshwater algae of the Northwest Territories, Canada. Can. J. Bot. 60, 1964-1997.

Sheath, R.G., Vis, M.L., Hambrook, J.A., Cole, K.M., 1996. Tundra stream macroalgae of North America: composition, distribution and physiological adaptations. Hydrobiology 336, 67-82.

Sicora, C., Máté, Z., Vass, I., 2003. The interaction of visible and UV-B light during photodamage and repair of photosystem II. Photosynth. Res. 75, 127-137.

Steinhoff, F.S., Wiencke, C., Müller, R., Bischof, K., 2008. Effects of ultraviolet radiation and temperature on the ultrastructure of zoospores of the brown macroalga Laminaria hyperborea. Plant Biol. 10, 388-397.

Stibal, M., Elster, J., Šabacká, M., Kaštovská, K., 2007. Seasonal and diel changes in photosynthetic activity of the snow alga Chlamydomonas nivalis (Chlorophyceae) from Svalbard determined by pulse amplitude modulation fluorometry. FEMS Microbiol. Ecol. 59, 265-273.

Stockmayer, S., 1906. Kleiner Beitrag zur Kenntnis der Süßwasseralgenflora Spitzbergens. Plant Syst. Evol. 56, 47-53.

Stoyneva, M.P., 2003. Survey on green algae of Bulgarian thermal springs. Biologia $58,563-574$

Teoh, M.-L., Chu, W.-L., Marchant, H., Phang, S.-M., 2004. Influence of culture temperature on the growth, biochemical composition and fatty acid profiles of six Antarctic microalgae. J. Appl. Phycol. 16, 421-430.

Turcsányi, E., Vass, I., 2000. Inhibition of photosynthetic electron transport of UV-A radiation targets the photosystem II complex. Photochem. Photobiol. 72, 513-520.

Vass, I., Turcsányi, E., Touloupakis, E., Ghanotakis, D., Petrouleas, V., 2002. The mechanism of UV-A radiation-induced inhibition of photosystem II electron transport studied by EPR and chlorophyll fluorescence. Biochemistry 41, $10200-10208$ 